\title{
Mangiferin inhibits macrophage classical activation via downregulating interferon regulatory factor 5 expression
}

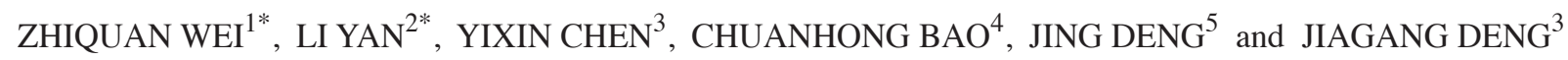 \\ ${ }^{1}$ Guangxi Scientific Experimental Center of Traditional Chinese Medicine; \\ ${ }^{2}$ Laboratory of Basis and Application Research of Zhuang Medicine Formulas, Zhuang Medicine College, \\ Guangxi University of Chinese Medicine; ${ }^{3}$ Guangxi Key Laboratory of Pharmacodynamics Studies of Traditional Chinese Medicine, \\ Nanning, Guangxi 530001; ${ }^{4}$ Department of Pharmacy, Ruikang Affiliated Hospital, Guangxi University of Chinese Medicine, \\ Nanning, Guangxi 530012, P.R. China; ${ }^{5}$ Dana-Farber Cancer Institute, Harvard Medical School, Boston, MA 02115, USA
}

Received June 6, 2015; Accepted May 12, 2016

DOI: $10.3892 / \mathrm{mmr} .2016 .5352$

\begin{abstract}
Mangiferin is a natural polyphenol and the predominant effective component of Mangifera indica Linn. leaves. For hundreds of years, Mangifera indica Linn. leaf has been used as an ingredient in numerous traditional Chinese medicine preparations for the treatment of bronchitis. However, the pharmacological mechanism of mangiferin in the treatment of bronchitis remains to be elucidated. Macrophage classical activation is important role in the process of bronchial airway inflammation, and interferon regulatory factor 5 (IRF5) has been identified as a key regulatory factor for macrophage classical activation. The present study used the THP-1 human monocyte cell line to investigate whether mangiferin inhibits macrophage classical activation via suppressing IRF5 expression in vitro. THP-1 cells were differentiated to macrophages by phorbol 12-myristate 13-acetate. Macrophages were polarized to M1 macrophages following stimulation with lipopolysaccharide (LPS)/interferon- $\gamma($ IFN- $\gamma)$. Flow cytometric analysis was conducted to detect the M1 macrophages. Reverse transcription-quantitative polymerase chain reaction was used to investigate cellular IRF5 gene expression. Levels of proinflammatory cytokines and IRF5 were assessed following cell culture and cellular homogenization using enzyme-linked immunosorbent assay. IRF5 protein and nuclei co-localization was performed in macrophages with laser scanning confocal microscope immunofluorescence analysis. The results of the present study demonstrated that mangiferin significantly
\end{abstract}

Correspondence to: Professor Jiagang Deng, Guangxi Key Laboratory of Pharmacodynamics Studies of Traditional Chinese Medicine, 179 Mingxiudong Road, Nanning, Guangxi 530001, P.R. China

E-mail:.jg_deng@hotmail.com

*Contributed equally

Key words: mangiferin, macrophage classical activation, interferon regulatory factor 5, anti-inflammation, M1 macrophage, THP-1 cells inhibits LPS/IFN- $\gamma$ stimulation-induced classical activation of macrophages in vitro and markedly decreases proinflammatory cytokine release. In addition, cellular IRF5 expression was markedly downregulated. These results suggest that the inhibitory effect of mangiferin on classical activation of macrophages may be exerted via downregulation of cellular IRF5 expression levels.

\section{Introduction}

Mangiferin, (1,3,6,7-tetrahydroxyxanthone-C2- $\beta$-D-gluco side) is a natural polyphenol (1), and the predominant effective component of Mangifera indica Linn. leaf (Fig. 1) (2-4). For hundreds of years, Mangifera indica Linn. leaves have been used in southern China as an ingredient in various traditional Chinese medicine preparations for the treatment of bronchitis. However, the underlying pharmacological mechanism of mangiferin in the treatment of bronchitis remains to be elucidated. Previous studies have demonstrated mangiferin exerts marked anti-inflammatory properties, and the pharmacological mechanism is associated with markedly decreased release of proinflammatory cytokines $(5,6)$. Bronchial airway inflammation is recognized as a characteristic pathological change in bronchitis (7). Peripheral blood monocytes migrate into the bronchus and surrounding lung tissue by chemotaxis. Monocytes in the lung tissue differentiates into macrophage and polarizes to M1 macrophages when activated by lipopolysaccharide (LPS) or interferon- $\gamma($ IFN- $\gamma)(8,9)$. This process is defined as macrophage classical activation (10). M1 macrophages produce and release large quantities of proinflammatory cytokines, including tumor necrosis factor- $\alpha$ (TNF- $\alpha$ ), interleukin-1 $\beta$ (IL-1 $\beta$ ), interleukin-6 (IL-6) and interleukin-8 (IL-8) (11,12). Proinflammatory cytokines are important in human infection and non-infection immunity, however, excessive proinflammatory cytokines may result in tissue and cell damage $(13,14)$. Serious tissue and cell damage can lead to deteriorating physiological function that may be life-threatening. Thus, M1 macrophages are crucial for the pathological process of bronchitis development. It may be a potential biological target of a therapeutic agent used to treat airway inflammation treatment, as targeting it may 
appropriately regulate polarization to M1 macrophages (15). Previous studies demonstrate that IRF5 is critical in macrophage polarization to M1 macrophages, as polarization can be inhibited by suppression of IRF5 expression in macrophages $(16,17)$. It remains to be elucidated whether mangiferin inhibits macrophage polarization to M1 macrophages via suppressing IRF5 expression, and thus decreasing proinflammatory cytokines releasing.

Primary human macrophages are difficult to isolate in sufficient quantities from tissue and do not proliferate in culture, and the obtained cells often exhibit notable phenotypic heterogeneity. Monocyte-derived macrophages, however, are a useful option, as human blood monocytes are readily available in large numbers and may be differentiated into macrophages in vitro (18). Thus, the present study used THP-1 human monocyte to investigate whether mangiferin inhibits classical activation of macrophages via suppressing IRF5 expression in vitro.

\section{Materials and methods}

Mangiferin preparation. Mangiferin was provided by the Key Laboratory of Traditional Chinese Medical Pharmacology, Guangxi University of Chinese Medicine (Nanning, China). It was isolated from leaves of Mangifera indica Linn. harvested in the Baise region of China. The preparation method was performed as described previously (19). At the end of the extraction process, a yellow powder with $97.5 \%$ purity was obtained (Fig. 1). Purity of the mangiferin powder was detected by high performance liquid chromatography (Fig. 2) (20). The HPLC measurement was performed on an Agilent 1100 LC system (Agilent, Santa Clara, CA, USA) and Elite Hypersil C18 column $(5 \mu \mathrm{m}, 4.6 \mathrm{mmIDx} 250 \mathrm{~mm})$, with a gradient system of acetonitrile- $0.1 \%$ phosphoric acid solution as a mobile phase at a flow rate of $1.0 \mathrm{ml} / \mathrm{min}$. The detective wavelength was $258 \mathrm{~nm}$, the column temperature was $30^{\circ} \mathrm{C}$.

Reagents and devices. Methyl thiazolyl tetrazolium (MTT), dimethyl sulfoxide (DMSO), phorbol 12-myristate 13-acetate (PMA), E. coli O55:B5 lipopolysaccharide (LPS) and IFN- $\gamma$ were obtained from Sigma-Aldrich (St. Louis, MO, USA). Fetal bovine serum (FBS), L-glutamine, RPMI 1640, NucBlue Fixed Cell ReadyProbes reagent, BlockAid Blocking Solution and Image-iT Fixation/Permeabilization kit were purchased from Invitrogen (Thermo Fisher Scientific, Inc., Waltham, MA, USA). Mouse anti-cluster of differentiation (CD) 86-PE monoclonal human antibody (cat. no. 555658; 1:20), mouse anti-CD80-FITC monoclonal antibody (cat. no. 555683; 1:20) and LSR Fortessa flow cytometer were obtained from BD Biosciences, Franklin Lakes, NJ, USA). Mouse anti-IRF5-eFluor 660 monoclonal antibodies was bought from eBioscience, Inc. (San Diego, CA, USA; cat. no. 50-9698; 1:20) and the Membrane and Cytoplasmic Protein Extraction kit was obtained from Sangon Biotech Co., Ltd., Shanghai, China). TNF- $\alpha$, IL-1 $\beta$, IL-6, IL- 8 and IRF5 ELISA kits were purchased from Cusabio (College Park, MD, USA). A Multiskan Spectrum 1500 microplate reader and Applied Biosystems 7500 Fast Real-Time PCR system were obtained from Thermo Fisher Scientific, Inc. TCS SP5 II laser scanning confocal microscope was purchased from Leica Microsystems
$\mathrm{GmbH}$ (Wetzlar, Germany) and QIAcube nucleic acid purification device was obtained from Qiagen $\mathrm{GmbH}$ (Hilden, Germany).

Cell culture and treatment. The THP-1 cell line was obtained from the Type Culture Collection of the Chinese Academy of Sciences (Shanghai, China), and maintained at $5 \times 10^{5}$ cells $/ \mathrm{ml}$ in RPMI 1640 medium supplemented with $10 \%$ FBS and $2 \mathrm{mmol} / \mathrm{l} \mathrm{L}$-glutamine at $37^{\circ} \mathrm{C}$ in $5 \% \mathrm{CO}_{2}$. THP-1 cells $\left(2 \times 10^{5}\right.$ cells $\left./ \mathrm{ml}\right)$ were differentiated to macrophages using $200 \mathrm{nmol} / \mathrm{l}$ PMA for 3 days as previously described by Daigneault et al (21). Following the initial 3 days stimulus, the PMA-containing media was removed and the cells were incubated in fresh RPMI 1640 medium supplemented with $10 \%$ FBS and $2 \mathrm{mmol} / \mathrm{l} \mathrm{L-glutamine.} \mathrm{The} \mathrm{cytotox-}$ icity of mangiferin was determined using the MTT assay. Macrophages $(2 \mathrm{ml} /$ well) were seeded in flat-bottom 24-well culture plates at a cell density of $5 \times 10^{5}$ cells $/ \mathrm{ml}$ at $37^{\circ} \mathrm{C}$ in a humidified incubator with $5 \% \mathrm{CO}_{2}$. Cells were allowed to attach and recover for $24 \mathrm{~h}$, and then the cells were treated with different concentrations of mangiferin $(0,12.5,25,50,100$ or $200 \mu \mathrm{mol} / \mathrm{l}$ ), which was dissolved in RPMI 1640 medium containing $0.1 \%$ DMSO. Cells treated with an equivalent volume of RPMI 1640 medium containing 0.1\% DMSO served as a blank control (control group). Following treatment with mangiferin or DMSO for $24 \mathrm{~h}$, the cells were washed twice in PBS and then incubated for $4 \mathrm{~h}$ with LPS $(1 \mu \mathrm{g} / \mathrm{ml})$ and IFN- $\gamma$ (20 $\mathrm{ng} / \mathrm{ml}$ ) to allow polarization to M1 macrophages according to a method previously described by Juhas et al (22). Cells without mangiferin treatment were regarded as the model control group (model group).

Flow cytometric analysis. Flow cytometric measurements were performed using an 11 color LSR Fortessa flow cytometer. Forward and side scatter light was used to identify cell population and measure size and granularity of the cells. Auto-fluorescence was recorded by analyzing unstained cells. Fc receptors were blocked by incubating cells with $100 \mu \mathrm{g}$ recombinant human IgG (from the Image-iT Fixation/Permeabilization kit; Invitrogen, Thermo Fisher Scientific, Inc.) for $15 \mathrm{~min}$ at $4^{\circ} \mathrm{C}$ prior to antibody staining. For detection of cell surface markers, $1 \mu \mathrm{g}$ CD86-PE and CD80-FITC antibodies were incubated with samples containing $3 \times 10^{5} \mathrm{THP}-1$ cells for $30 \mathrm{~min}$ at $4^{\circ} \mathrm{C}$. Following incubation, all cells were washed in PBS and fluorescence was compared to unstained controls with 10,000 events recorded. A gate with $\mathrm{CD} 86-\mathrm{PE}^{+}$and $\mathrm{CD} 80-\mathrm{FITC}^{+}$was configured to select M1 macrophages. The FlowJo for Windows of version 7.1 (Emerald Biotech Co. Ltd, Hangzhou, China) was used for analysis.

Confocal microscopy analysis. Following washing twice in PBS, cells in the culture dishes were incubated for fixation and permeabilization using Image-iT Fixation/Permeabilization kit. Blocking solution was added following removal of the permeabilization solution and washing twice with PBS. Subsequently, $1 \mu \mathrm{g}$ of monoclonal anti-human IRF5-eFluor 660 antibodies and 2 drops of DAPI NucBlue Fixed Cell ReadyProbes reagent were added, and incubated with cells for $30 \mathrm{~min}$ at $4^{\circ} \mathrm{C}$ in the dark. Images of whole cell 


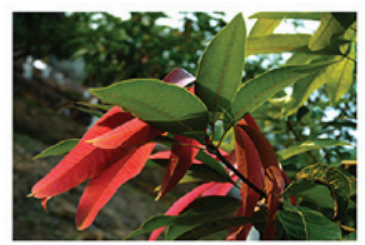

Mangifera indica linn. leave

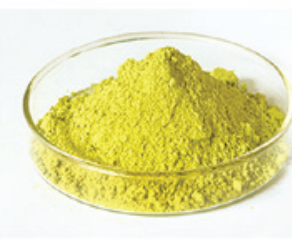

Mangiferin powder<smiles>O=c1c2cc(O)c(O)cc2oc2cc(O)c(C3(O)O[C@H](CO)[C@@H](O)[C@H](O)[C@H]3O)c(O)c12</smiles>

Mangiferin chemically structural formula

Figure 1. Mangifera indica Linn. leaves, mangiferin powder and the chemical structure.
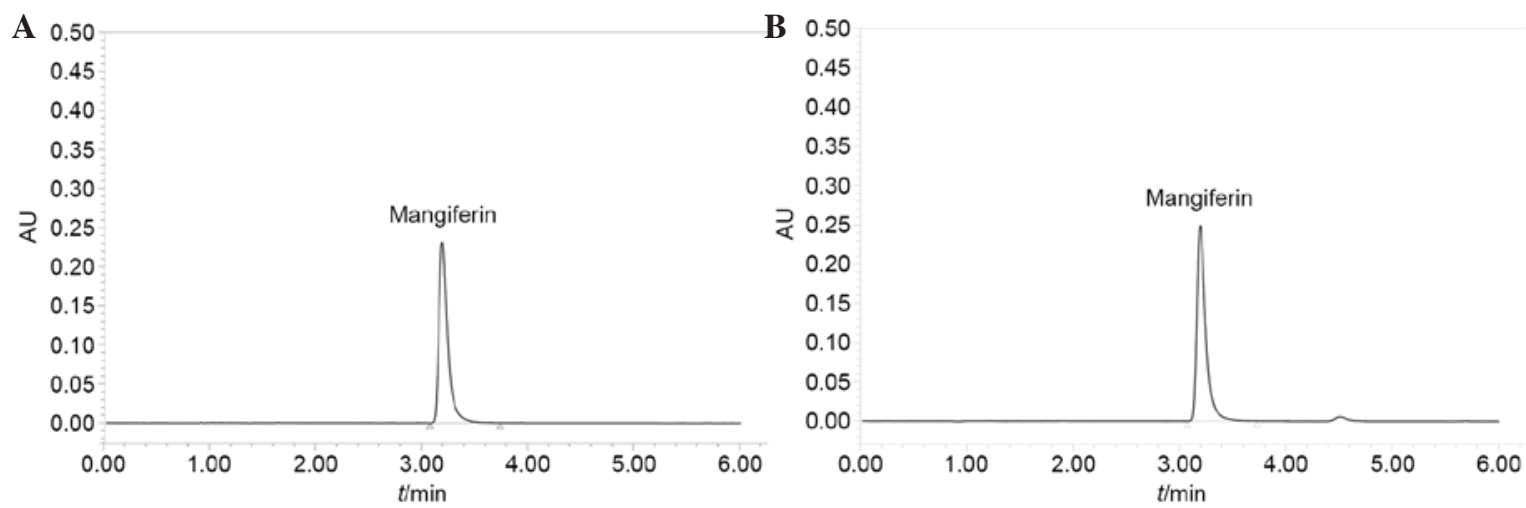

Figure 2. High performance liquid chromatograms of (A) mangiferin standard substance and (B) sample. AU, arbitrary units.

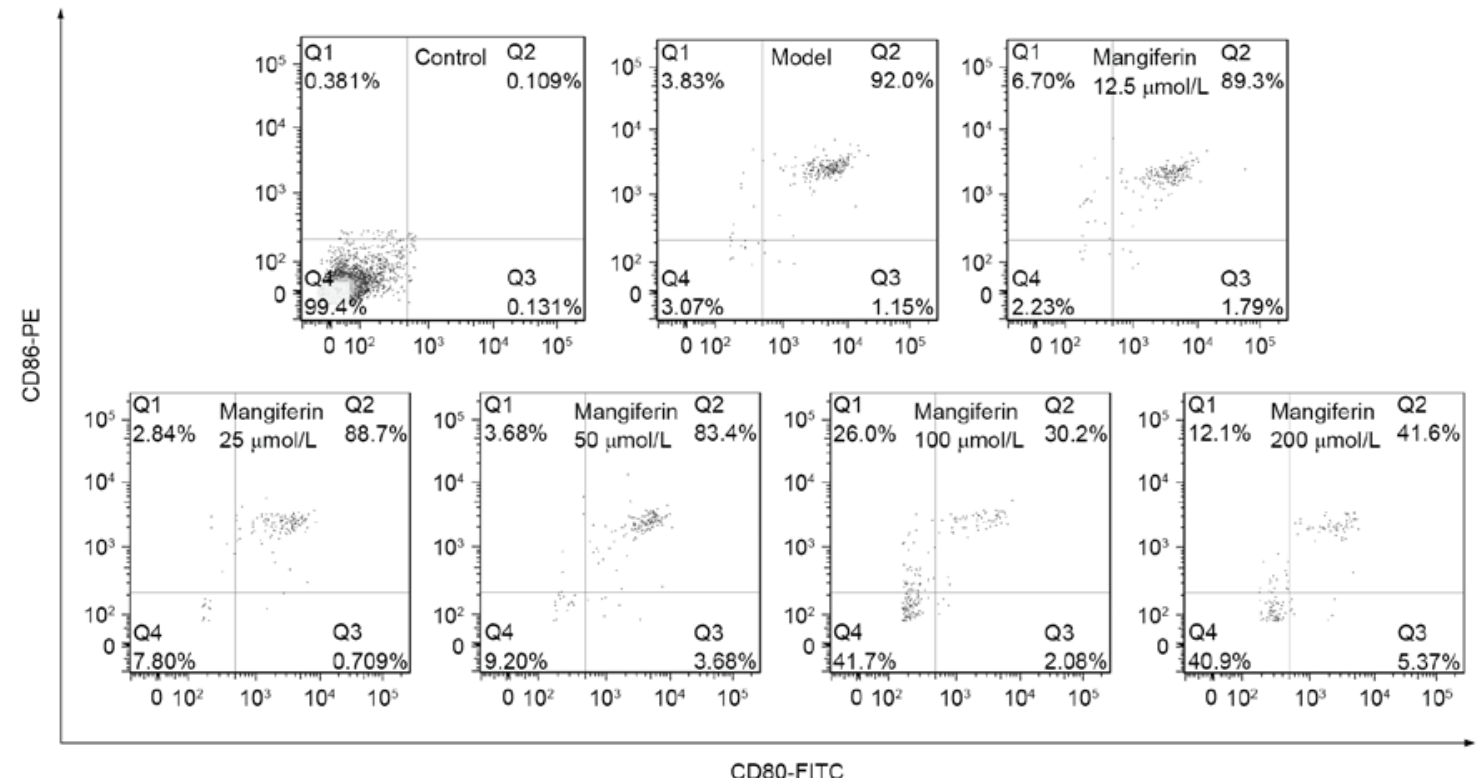

Figure 3. Flow cytometry dot plot of $\mathrm{CD} 80^{+} / \mathrm{CD} 6^{+} \mathrm{M} 1$ macrophages in each group. Macrophages polarized to M1 macrophages following lipopolysaccharide/ interferon- $\gamma$ stimulation. Flow cytometric analysis was conducted to detect the M1 macrophages stained with anti-human CD86-PE and anti-human CD80-FITC. M1 macrophages were calculated and shown in second quadrant. CD, cluster of differentiation; PE, phycoerythrin; FITC, fluorescein isothiocyantate.

morphology and IRF5 staining were acquired using a Leica TCS SP5 II laser scanning confocal microscope.

Reverse transcription-quantitative polymerase chain reaction $(R T-P C R)$. RNA was isolated and purified from cell homogenates using RNeasy Plus Mini kit on a QIAcube nucleic acid purification device. RNA was reverse transcribed with QuantScript RT kit according to the manufacturer's protocol. The primer and MGB-probe used to analyze IRF-5 gene expression were designed and supplied by Invitrogen (Thermo Fisher Scientific, Inc.), the sequences are as follows: Forward, 5'-GTTGTTAAA GAGCCTGGCACCTA-3' and reverse, 5'-CTGGAGTGTGCA GAGATGACACA-3' for the primer; and 5'-CCGCTCTCA CTTCAT-3' for the MGB-probe. RT-PCR was conducted on an ABI 7500 system. Samples were run in triplicate. The thermocycling conditions were as follows: $95^{\circ} \mathrm{C}$ for $5 \mathrm{~min} ; 40$ cycles of $95^{\circ} \mathrm{C}$ for $30 \mathrm{sec}$ and $60^{\circ} \mathrm{C}$ for $90 \mathrm{sec}$. Data were collected at the end of each cycle. Gene copies were calculated from a standard 

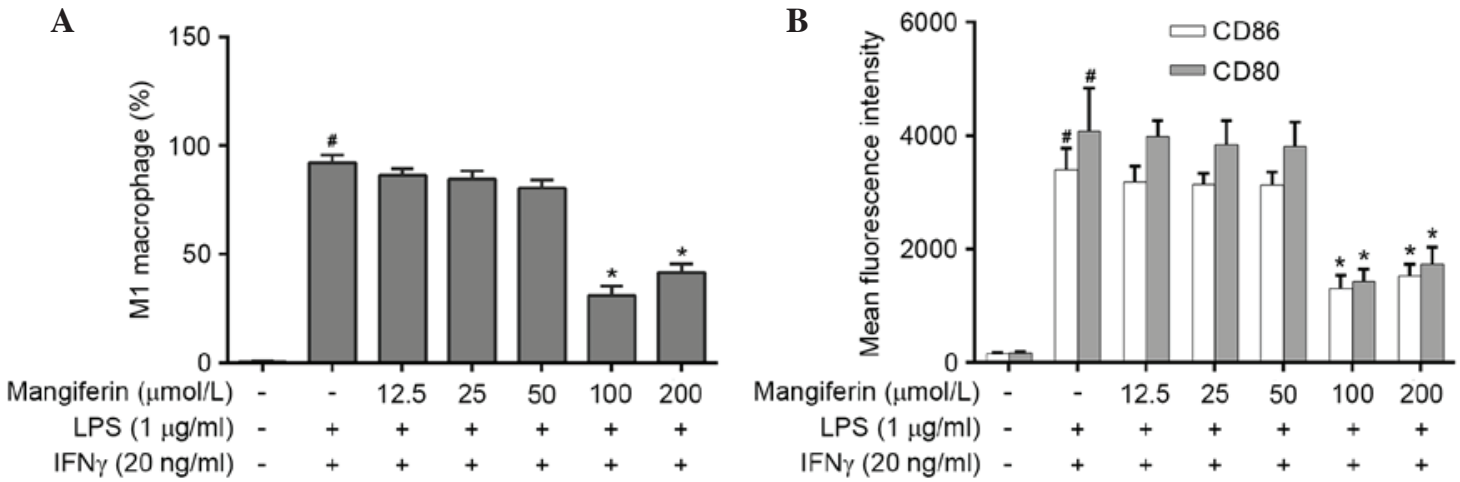

Figure 4. Bar plots of (A) mean percentage of M1 macrophages and (B) mean fluorescence intensity of $\mathrm{CD} 80^{+} / \mathrm{CD} 86^{+}$in each group. Data are expressed as the mean \pm standard deviation. ${ }^{~} \mathrm{P}<0.01$ vs. the control; ${ }^{*} \mathrm{P}<0.01$ vs. the model. $\mathrm{CD}$, cluster of differentiation; LPS, lipopolysaccharide; IFN, interferon.

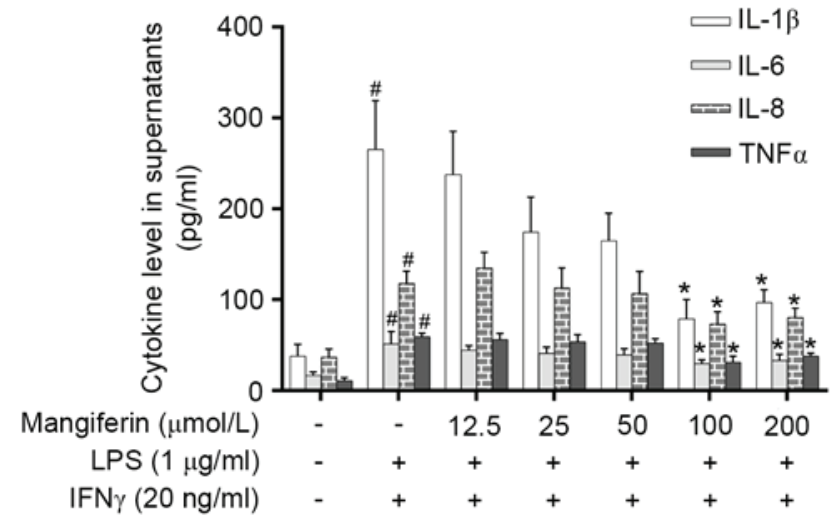

Figure 5. Levels of TNF- $\alpha$, IL-1 $\beta$, IL-6 and IL-8 in the supernatant of each group. LPS/IFN- $\gamma$ stimulation upregulated the levels of TNF- $\alpha$, IL-1 $\beta$, IL-6 and IL-8 levels in the model group. Mangiferin at doses of 100 and $200 \mu \mathrm{mol} / 1$ markedly decreased the levels of TNF- $\alpha$, IL- $1 \beta$, IL-6 and IL-8 Data are expressed as the mean \pm standard deviation. ${ }^{~} \mathrm{P}<0.01$ vs. the control. ${ }^{*} \mathrm{P}<0.01$ vs. the model. TNF- $\alpha$, tumor necrosis factor- $\alpha$; IL, interleukin; LPS, lipopolysaccharide; IFN- $\gamma$, interferon- $\gamma$.

curve. The PCR results were analyzed with the 7500 software 2.0 included with the in ABI 7500 real-time quantitative PCR system (Thermo Fisher Scientific, Inc.) (23).

Proinflammatory cytokine and IRF5 protein ELISA. Cells were washed twice in PBS. The cell protein was extracted with Membrane and Cytoplasmic Protein Extraction kit, the supernatants were collected $\left(300 \mathrm{x} \mathrm{g}\right.$ for $5 \mathrm{~min}$ at $\left.4^{\circ} \mathrm{C}\right)$ and cryopreserved at $-20^{\circ} \mathrm{C}$ for the ELISA assays. ELISA kits were used to assess the concentrations of TNF- $\alpha$, IL-1 $\beta$, IL- 6 , IL-8 and IRF5 according to the manufacturer's protocols.

Statistical analysis. All data were analyzed for statistical significance using SPSS 13.0 software (SPSS Inc., Chicago, IL, USA). Data are presented as the mean \pm standard deviation. Statistical analysis was conducted using one-way analysis of variance. $\mathrm{P}<0.05$ was considered to indicate a statistically significant difference.

\section{Results}

Effect of mangiferin on macrophage polarization towards MI macrophages. A commonly accepted marker profile for M1 macrophages is $\mathrm{CD}^{+} 0^{+} / \mathrm{CD} 86^{+}$. Cells with $\mathrm{CD} 80^{+}$and $\mathrm{CD} 86^{+}$ surface markers can be identified as M1 macrophage (24). The present study observed few cells with $\mathrm{CD} 80^{+} / \mathrm{CD} 86^{+}$ surface markers prior to LPS/IFN- $\gamma$ stimulation, while large quantities of M1 macrophages with high fluorescence intensity of $\mathrm{CD} 80^{+} / \mathrm{CD} 86^{+}$surface markers were detected following LPS/IFN- $\gamma$ stimulation (Figs. 3 and 4). Following treatment with different concentrations of mangiferin, the percentage of M1 macrophages in each mangiferin-treated group was reduced to various degrees. However, there was a statistically significant decrease in M1 macrophage percentage and cell $\mathrm{CD} 0^{+} / \mathrm{CD} 86^{+}$surface markers mean fluorescence intensity in the 100 and $200 \mu \mathrm{mol} / 1$ mangiferin groups $(\mathrm{P}<0.01)$. Furthermore, the decreases in the $100 \mu \mathrm{mol} / 1$ mangiferin group was lower than in the $200 \mu \mathrm{mol} / 1$ group, but there was no significant difference between the two groups (Figs. 3 and 4).

Effect of mangiferin on cytokine levels in the supernatant. With LPS/IFN- $\gamma$ stimulation, macrophages polarized to M1 macrophages and released large quantities of proinflammatory cytokines, including TNF- $\alpha$, IL-1 $\beta$, IL- 6 and IL- 8 . Thus, these proinflammatory cytokines in the supernatant can indicate the classical activation of macrophages. In the present study, the levels of TNF- $\alpha$, IL-1 $\beta$, IL-6 and IL- 8 levels in the cell culture supernatants were increased by LPS/IFN- $\gamma$ stimulation, and were significantly higher in the model group compared with the control group $(\mathrm{P}<0.01$; Fig. 5). Following treatment with various concentrations of mangiferin, the TNF- $\alpha$, IL- $1 \beta$, IL-6 and IL-8 were significantly decreased by mangiferin at doses of 100 and $200 \mu \mathrm{mol} / 1(\mathrm{P}<0.01)$, but not at other doses. Furthermore, the decrease in the $100 \mu \mathrm{mol} / 1$ mangiferin group was lower than in $200 \mu \mathrm{mol} / 1$, however, there was no significant difference between the two groups (Fig. 5).

Effect of mangiferin on macrophage IRF5 expression. An important role for IRF5 in macrophage classical activation has been previously recognized $(16,22)$. IRF5 is expressed at the highest levels in M1 macrophages (17,25). In the present study, macrophages in the control group expressed low gene and protein levels of IRF5, but significant increases in IRF5 gene and protein expression was observed in the model group and higher than in the control group $(\mathrm{P}<0.01$; Fig. 6). Following treatment with various concentrations of mangiferin, IRF5 expression levels were significantly decreased by mangiferin 

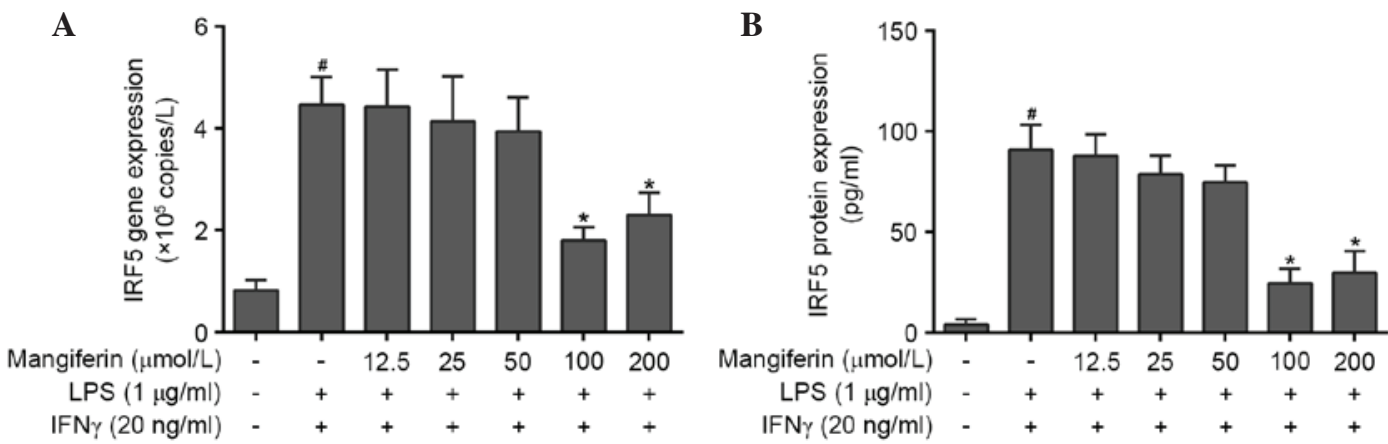

Figure 6. Bar plots of IRF5 (A) gene and (B) protein expression in each group. Data are expressed as the mean \pm standard deviation. ${ }^{\#} \mathrm{P}<0.01$ vs. the control; ${ }^{*} \mathrm{P}<0.01$ vs. the model. IFR5, interferon regulatory factor 5; LPS, lipopolysaccharide; IFN- $\gamma$, interferon- $\gamma$.
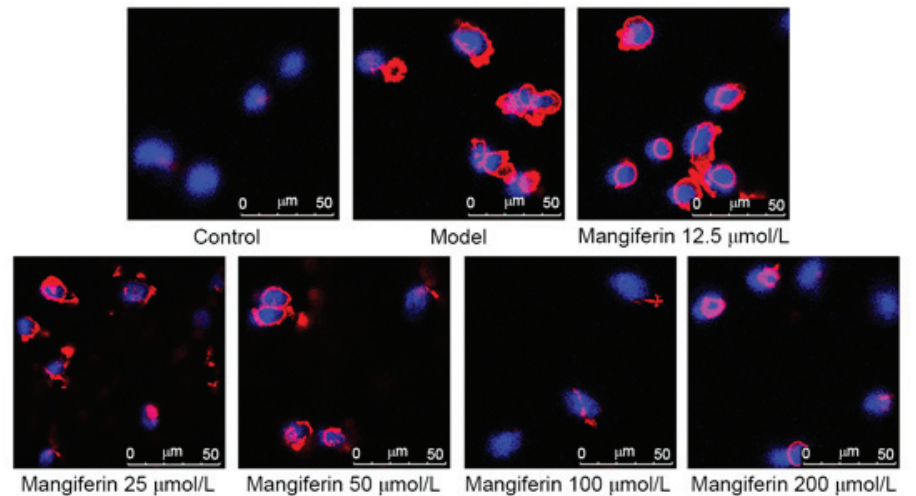

Figure 7. Laser scanning confocal microscope immunofluorescence analysis of IRF5 protein expression in macrophages and nucleus co-localization. Cells were stained using monoclonal anti-human IRF5-eFluor 660 antibody (red) and the blue pseudo color is a result of DAPI staining. IRF5, interferon regulatory factor 5 .

at doses of 100 and $200 \mu \mathrm{mol} / 1(\mathrm{P}<0.01$; Fig. 6), but not at other doses. Furthermore, the decrease in $100 \mu \mathrm{mol} / 1$ mangiferin group was lower than in the $200 \mu \mathrm{mol} / 1$ group, however, there was no significant difference between the two groups (Fig. 6).

Localization of IRF5 protein expression as observed by confocal microscopy. IRF5 has been reported to be important during macrophage polarization to M1 macrophages $(26,27)$. IRF5 protein was detected and nucleus co-localization was observed using fluorescence confocal microscopy to evaluate the effect of mangiferin on of IRF5 protein expression during macrophage polarization to M1 macrophages. Without LPS/IFN- $\gamma$ stimulation, IRF5 protein expression level was low. However, following stimulation by LPS/IFN- $\gamma$, IRF5 protein expression was significantly increased (Fig. 7). Following treatment with various concentrations of mangiferin, IRF5 protein expression levels were significantly decreased by mangiferin at doses of 100 and $200 \mu \mathrm{mol} / \mathrm{l}$ (Fig. 7). Furthermore, $100 \mu \mathrm{mol} / 1$ mangiferin resulted in a greater decrease in IRF5 protein expression levels than $200 \mu \mathrm{mol} / \mathrm{l}$ (Fig. 7).

\section{Discussion}

Previous studies have demonstrated that mangiferin exerts a number of beneficial biological effects on inflammation (28), oxidative injury (29), tumor cell growth (30), microorganism infections (31), metabolic regulations (32), immune regulations (33) and radioprotection (34). Among these pharmacological activities of mangiferin, its anti-inflammatory activity appears particularly prominently due to its beneficial effects against acute or chronic inflammation with various causes (35-39). Previous studies have also reported mangiferin exerts an anti-inflammatory effect via altering the biological behavior of macrophages to exert its anti-inflammatory activity $(40,41)$, however its sub-cellular target and molecular mechanism remain to be elucidated. Similarly, further research is required to understand the effect of mangiferin on classical activation of macrophages, which is vital for inflammation. IRF5 has been recognized as a key regulatory factor in macrophage classical activation $(27,42)$. However, little is known about the association between IRF5 and the effects of mangiferin on macrophage classical activation and, thus, further research is required.

As a member of the interferon regulatory factor family of transcription factors, IRF5 is closely associated with the inflammatory reaction and autoimmune response $(43,44)$. Previous studies demonstrate inflammatory and autoimmune diseases may be associated with increased IRF5 expression levels $(45,46)$. IRF5 is also an important regulatory factor in cell signal transduction pathway from Toll-like receptor (TLR) 7 to TLR9 $(47,48)$. IRF5 can regulate the release of multiple cytokines, including TNF- $\alpha$, IL- $1 \beta$, IL-6 and a number of chemokines, suggesting the inflammatory reaction is adjusted and controlled by IRF5 (49).

IRF5 is highly expressed in monocytes, macrophages and plasmacytoid dendritic cells, however, it is also expressed in 
B cells and T cells $(50,51)$. An important role for IRF5 in the macrophage classical activation has been identified. In M1 macrophages, IRF5 directly upregulates expression of multiple proinflammatory cytokines, but suppresses IL-10 expression, an anti-inflammatory cytokine $(25,52)$. Furthermore, exogenous expression of IRF5 in M1 or M2-polarized (alternatively activated) macrophages induces expression of M1-associated cytokines and chemokines (16). Thus, high expression levels of IRF5 is characteristic of M1 macrophages, in which it directly activates transcription of the genes encoding various proinflammatory cytokines. Thus, the present study hypothesizes that macrophage classical activation may be inhibited via suppressing IRF5 expression in M1 macrophages using a therapeutic agent.

The cell surface markers of M1 macrophages, remain disputed, however, previous studies have reported that classically activated macrophages (M1 macrophages) exhibit high levels of CD80 and CD86 markers (53), and their upregulated expression is associated with the release of a large quantity of inflammatory cytokines $(54,55)$. Thus, CD $80^{+} / \mathrm{CD}^{2} 6^{+}$ cytomembrane markers have been widely accepted as cell surface markers for M1 macrophages. Consistent with a previous study (24), cell with $\mathrm{CD} 80^{+} / \mathrm{CD}^{+} 6^{+}$surface markers were identified as M1 macrophage in the present study. Macrophages exhibited few $\mathrm{CD} 80^{+} / \mathrm{CD} 86^{+}$surface markers prior to LPS/IFN- $\gamma$ stimulation, and reduced proinflammatory cytokine levels in cell culture supernatant and lower cellular IRF5 expression were also observed. However, CD80 ${ }^{+} / \mathrm{CD}^{+} 6^{+}$ cells and levels of proinflammatory cytokines were markedly increased following LPS/IFN- $\gamma$ stimulation, and cellular IRF5 expression was markedly upregulated. These results indicated LPS/IFN- $\gamma$ stimulation results in macrophage M1 polarization, and was consistent with previous studies $(56,57)$.

Subsequent experiment results demonstrated that 100 and $200 \mu \mathrm{mol} / \mathrm{l}$ of mangiferin significantly inhibited LPS/IFN- $\gamma$ stimulation-induced macrophage polarization in vitro $(\mathrm{P}<0.01)$, and the inhibition of $100 \mu \mathrm{mol} / 1$ of mangiferin was more marked than $200 \mu \mathrm{mol} / 1$. Similarly, mangiferin results in the most notable inhibitory effect on cellular IRF5 expression at $100 \mu \mathrm{mol} / 1$ rather than $200 \mu \mathrm{mol} / 1$. These results suggest the effect of mangiferin was not improved at the highest dose when mangiferin was used to inhibit macrophage classical activation, however, the reason remains to be elucidated. Notably, the results of the present study also indicate a possible association between the inhibitory effect of mangiferin on macrophage classical activation and decreasing cellular IRF5 expression. Mangiferin may downregulate cellular IRF5 expression, which then affects macrophage classical activation. The results of the present study may provide further experimental support for research into the anti-inflammatory properties of mangiferin and its underlying mechanism.

Macrophage classical activation is required in the normal protective immune response (58), particularly, in the early stage of the inflammatory reaction. However, chronic inflammatory diseases or excessive inflammation injury are not part of the normal protective response and immoderate macrophage polarization to M1 macrophages has been considered to be an important factor in chronic bronchitis or other inflammatory diseases $(59,60)$. Mangiferin may inhibit macrophage classical activation via suppressing IRF5 expression levels. Thus, mangiferin results in beneficial effects against diseases with marked macrophage classical activation. This pharmacological effect suggest mangiferin may be a potential anti-inflammatory therapeutic agent.

In conclusion, mangiferin can inhibit classical macrophage activation in vitro. The depression of cellular IRF5 expression was shown to be closely associated with this effect. However, more research is required to fully elucidate the mechanism of action of mangiferin.

\section{Acknowledgements}

The present study was supported by the National Natural Science Foundation of China (grant no. 81260666), the Guangxi Key Laboratory of Pharmacodynamics Studies of Traditional Chinese Medicine (grant no. 14-A-01-03). The authors would also like to thank all the staff of Guangxi College and University Laboratory of Basis and Application Research of Zhuang Medicine Formulas for their helpful technical assistance.

\section{References}

1. Sun Y, Zhang X, Xue X, Zhang Y, Xiao H and Liang X: Rapid identification of polyphenol C-glycosides from Swertia franchetiana by HPLC-ESI-MS-MS. J Chromatogr Sci 47: 190-196, 2009.

2. Pardo-Andreu GL, Paim BA, Castilho RF, Velho JA, Delgado R, Vercesi AE and Oliveira HC: Mangifera indica L. extract (Vimang) and its main polyphenol mangiferin prevent mitochondrial oxidative stress in atherosclerosis-prone hypercholesterolemic mouse. Pharmacol Res 57: 332-338, 2008.

3. Pardo-Andreu GL, Dorta DJ, Delgado R, Cavalheiro RA, Santos AC, Vercesi AE and Curti C: Vimang (Mangifera indica L. extract) induces permeability transition in isolated mitochondria, closely reproducing the effect of mangiferin, Vimang's main component. Chem Biol Interact 159: 141-148, 2006.

4. Daud NH, Aung CS, Hewavitharana AK, Wilkinson AS, Pierson JT, Roberts-Thomson SJ, Shaw PN, Monteith GR, Gidley MJ and Parat MO: Mango extracts and the mango component mangiferin promote endothelial cell migration. J Agric Food Chem 58: 5181-5186, 2010.

5. Wei ZQ, Yan L, Deng JG and Deng J: Mangiferin protects rats against chronic bronchitis via regulating NF-kappaB (P65) and IkappaBalpha expression in mononuclear cells. Yao Xue Xue Bao 49: 596-601, 2014 (In Chinese).

6. Gong $\mathrm{X}$, Zhang L, Jiang R, Ye M, Yin X and Wan J: Anti-inflammatory effects of mangiferin on sepsis-induced lung injury in mice via up-regulation of heme oxygenase-1. J Nutr Biochem 24: 1173-1181, 2013.

7. Snoeck-Stroband JB, Lapperre TS, Gosman MM, Boezen HM, Timens W, ten Hacken NH, Sont JK, Sterk PJ and Hiemstra PS; Groningen Leiden Universities Corticosteroids in Obstructive Lung Disease (GLUCOLD) Study Group: Chronic bronchitis sub-phenotype within COPD: Inflammation in sputum and biopsies. Eur Respir J 31: 70-77, 2008.

8. Marchant JM, Gibson PG, Grissell TV, Timmins NL, Masters IB and Chang AB: Prospective assessment of protracted bacterial bronchitis: Airway inflammation and innate immune activation. Pediatr Pulmonol 43: 1092-1099, 2008.

9. Kim KW, Jee HM, Park YH, Choi BS, Sohn MH and Kim KE: Relationship between amphiregulin and airway inflammation in children with asthma and eosinophilic bronchitis. Chest 136: 805-810, 2009.

10. Varin A and Gordon S: Alternative activation of macrophages: Immune function and cellular biology. Immunobiology 214: 630-641, 2009.

11. Fong CH, Bebien M, Didierlaurent A, Nebauer R, Hussell T, Broide D, Karin M and Lawrence T: An antiinflammatory role for IKKbeta through the inhibition of 'classical' macrophage activation. J Exp Med 205: 1269-1276, 2008. 
12. Classen A, Lloberas J and Celada A: Macrophage activation: Classical versus alternative. Methods Mol Biol 531: 29-43, 2009.

13. Park KR and Bryers JD: Effect of macrophage classical (M1) activation on implant-adherent macrophage interactions with Staphylococcus epidermidis: A murine in vitro model system. J Biomed Mater Res A 100: 2045-2053, 2012.

14. Sunil VR, Patel-Vayas K, Shen J, Laskin JD and Laskin DL: Classical and alternative macrophage activation in the lung following ozone-induced oxidative stress. Toxicol Appl Pharmacol 263: 195-202, 2012.

15. Draijer C, Robbe P, Boorsma CE, Hylkema MN and Melgert BN: Characterization of macrophage phenotypes in three murine models of house-dust-mite-induced asthma. Mediators Inflamm 2013: 632049, 2013

16. Krausgruber T, Blazek K, Smallie T, Alzabin S, Lockstone H, Sahgal N, Hussell T, Feldmann M and Udalova IA: IRF5 promotes inflammatory macrophage polarization and TH1-TH17 responses. Nat Immunol 12: 231-238, 2011.

17. Weiss M, Blazek K, Byrne AJ, Perocheau DP and Udalova IA: IRF5 is a specific marker of inflammatory macrophages in vivo. Mediators Inflamm 2013: 245804, 2013.

18. Wang M, Wang F, Yang J, Zhao D, Wang H, Shao F, Wang W, Sun R, Ling M, Zhai J and Song S: Mannan-binding lectin inhibits Candida albicans-induced cellular responses in PMA-activated THP-1 cells through Toll-like receptor 2 and Toll-like receptor 4 PLoS One 8: e83517, 2013.

19. Deng JG LXJ and Du ZC: A preparation method of mangiferin: China 10197398. (2013-2006-05).

20. Dai R, Gao J and Bi K: High-performance liquid chromatographic method for the determination and pharmacokinetic study of mangiferin in plasma of rats having taken the traditional Chinese medicinal preparation $\mathrm{Zi}$-Shen pill. J Chromatogr Sci 42: 88-90, 2004.

21. Daigneault M, Preston JA, Marriott HM, Whyte MK and Dockrell DH: The identification of markers of macrophage differentiation in PMA-stimulated THP-1 cells and monocyte-derived macrophages. PLoS One 5: e8668, 2010.

22. Juhas U, Ryba-Stanislawowska M, Szargiej P and Myśliwska J: Different pathways of macrophage activation and polarization. Postepy Hig Med Dosw (Online) 69: 496-502, 2015.

23. García-Bermúdez M, López-Mejías R, Genre F, et al: Interferon regulatory factor 5 genetic variants are associated with cardiovascular disease in patients with rheumatoid arthritis. Arthritis Res Ther 16: R146, 2014

24. Menzies FM, Henriquez FL, Alexander J and Roberts CW: Sequential expression of macrophage anti-microbial/inflammatory and wound healing markers following innate, alternative and classical activation. Clin Exp Immunol 160: 369-379, 2010.

25. Chionh YT, Ng GZ, Ong L, Arulmuruganar A, Stent A, Saeed MA, Wee JL and Sutton P: Protease-activated receptor 1 suppresses Helicobacter pylori gastritis via the inhibition of macrophage cytokine secretion and interferon regulatory factor 5. Mucosal Immunol 8: 68-79, 2015.

26. Ferrante CJ and Leibovich SJ: Regulation of macrophage polarization and wound healing. Adv Wound Care (New Rochelle) 1: 10-16, 2012.

27. Yanagimachi M, Naruto T, Miyamae T, Hara T, Kikuchi M, Hara R, Imagawa T, Mori M, Sato H, Goto $\mathrm{H}$ and Yokota $\mathrm{S}$ : Association of IRF5 polymorphisms with susceptibility to macrophage activation syndrome in patients with juvenile idiopathic arthritis. J Rheumatol 38: 769-774, 2011.

28. Wei Z, Yan L, Deng J and Deng J: Effects of mangiferin on MAPK signaling pathway in chronic inflammation. Zhongguo Zhong Yao Za Zhi 36: 1798-1802, 2011 (In Chinese).

29. Márquez L, García-Bueno B, Madrigal JL and Leza JC: Mangiferin decreases inflammation and oxidative damage in rat brain after stress. Eur J Nutr 51: 729-739, 2012

30. Li H, Huang J, Yang B, Xiang T, Yin X, Peng W, Cheng W, Wan J, Luo F, Li H and Ren G: Mangiferin exerts antitumor activity in breast cancer cells by regulating matrix metalloproteinases, epithelial to mesenchymal transition, and $\beta$-catenin signaling pathway. Toxicol Appl Pharmacol 272: $180-190,2013$

31. Bock $\mathrm{C}$ and Ternes $\mathrm{W}$ : The phenolic acids from bacterial degradation of the mangiferin aglycone are quantified in the feces of pigs after oral ingestion of an extract of Cyclopia genistoides (honeybush tea). Nutr Res 30: 348-357, 2010.

32. Lim J, Liu Z, Apontes P, Feng D, Pessin JE, Sauve AA, Angeletti RH and Chi Y: Dual mode action of mangiferin in mouse liver under high fat diet. PLoS One 9: e90137, 2014.
33. Rajendran P, Jayakumar T, Nishigaki I, Ekambaram G, Nishigaki Y,Vetriselvi Jand SakthisekaranD:Immunomodulatory effect of mangiferin in experimental animals with benzo(a) pyrene-induced lung carcinogenesis. Int J Biomed Sci 9: 68-74, 2013.

34. Menkovic N, Juranic Z, Stanojkovic T, Raonic-Stevanovic T, Savikin K, Zdunić G and Borojevic N: Radioprotective activity of Gentiana lutea extract and mangiferin. Phytother Res 24: 1693-1696, 2010

35. Carvalho RR, Pellizzon CH, Justulin L Jr, Felisbino SL, Vilegas W, Bruni F, Lopes-Ferreira M and Hiruma-Lima CA: Effect of mangiferin on the development of periodontal disease: Involvement of lipoxin A4, anti-chemotaxic action in leukocyte rolling. Chem Biol Interact 179: 344-350, 2009

36. Garrido G, González D, Lemus Y, Delporte C and Delgado R: Protective effects of a standard extract of Mangifera indica L. (VIMANG) against mouse ear edemas and its inhibition of eicosanoid production in $\mathrm{J} 774$ murine macrophages. Phytomedicine 13: 412-418, 2006.

37. Petrova A, Davids LM, Rautenbach F and Marnewick JL: Photoprotection by honeybush extracts, hesperidin and mangiferin against UVB-induced skin damage in SKH-1 mice. J Photochem Photobiol B 103: 126-139, 2011.

38. Kasbe P, Jangra A and Lahkar M: Mangiferin ameliorates aluminium chloride-induced cognitive dysfunction via alleviation of hippocampal oxido-nitrosative stress, proinflammatory cytokines and acetylcholinesterase level. J Trace Elem Med Biol 31: 107-112, 2015

39. Wang B, Wan J, Gong X, Kuang G, Cheng X and Min S: Mangiferin attenuates renal ischemia-reperfusion injury by inhibiting inflammation and inducing adenosine production. Int Immunopharmacol 25: 148-154, 2015.

40. Dou W, Zhang J, Ren G, Ding L, Sun A, Deng C, Wu X, Wei X, Mani S and Wang Z: Mangiferin attenuates the symptoms of dextran sulfate sodium-induced colitis in mice via NF- $\mathrm{kB}$ and MAPK signaling inactivation. Int Immunopharmacol 23: 170-178, 2014

41. De A and Chattopadhyay S: The variation in cytoplasmic distribution of mouse peritoneal macrophage during phagocytosis modulated by mangiferin, an immunomodulator. Immunobiology 214: 367-376, 2009

42. Yanagimachi M, Goto H, Miyamae T, Kadota K, Imagawa T, Mori M, Sato H, Yanagisawa R, Kaneko T, Morita S, et al: Association of IRF5 polymorphisms with susceptibility to hemophagocytic lymphohistiocytosis in children. J Clin Immunol 31: 946-951, 2011.

43. Tang L, Chen B, Ma B and Nie S: Association between IRF5 polymorphisms and autoimmune diseases: A meta-analysis. Genet Mol Res 13: 4473-4485, 2014.

44. Clark DN, Lambert JP, Till RE, Argueta LB, Greenhalgh KE, Henrie B, Bills T, Hawkley TF, Roznik MG, Sloan JM, et al: Molecular effects of autoimmune-risk promoter polymorphisms on expression, exon choice, and translational efficiency of interferon regulatory factor 5. J Interferon Cytokine Res 34: 354-365, 2014.

45. Chua KH, Lian LH, Khor WC, Lee WS, Hilmi I, Goh KL and Kee BP: Association between genetic polymorphisms in interferon regulatory factor 5 (IRF5) gene and Malaysian patients with Crohn's disease. J Dig Dis 16: 205-216, 2015.

46. Feng D, Stone RC, Eloranta ML, Sangster-Guity N, Nordmark G, Sigurdsson S, Wang C, Alm G, Syvänen AC, Rönnblom L and Barnes BJ: Genetic variants and disease-associated factors contribute to enhanced interferon regulatory factor 5 expression in blood cells of patients with systemic lupus erythematosus. Arthritis Rheum 62: 562-573, 2010.

47. Balkhi MY, Fitzgerald KA and Pitha PM: Functional regulation of MyD88-activated interferon regulatory factor 5 by K63-linked polyubiquitination. Mol Cell Biol 28: 7296-7308, 2008.

48. Yasuda K, Nündel K, Watkins AA, Dhawan T, Bonegio RG, Ubellacker JM, Marshak-Rothstein A and Rifkin IR: Phenotype and function of B cells and dendritic cells from interferon regulatory factor 5-deficient mice with and without a mutation in DOCK2. Int Immunol 25: 295-306, 2013.

49. Steinhagen F, McFarland AP, Rodriguez LG, Tewary P, Jarret A, Savan R and Klinman DM: IRF-5 and NF- $\mathrm{kB}$ p50 co-regulate IFN- $\beta$ and IL- 6 expression in TLR9-stimulated human plasmacytoid dendritic cells. Eur J Immunol 43: 1896-1906, 2013.

50. Savitsky DA, Yanai H, Tamura T, Taniguchi T and Honda K: Contribution of IRF5 in B cells to the development of murine SLE-like disease through its transcriptional control of the IgG2a locus. Proc Natl Acad Sci USA 107: 10154-10159, 2010. 
51. Mancl ME, Hu G, Sangster-Guity N, Olshalsky SL, Hoops K, Fitzgerald-Bocarsly P, Pitha PM, Pinder K and Barnes BJ: Two discrete promoters regulate the alternatively spliced human interferon regulatory factor-5 isoforms. Multiple isoforms with distinct cell type-specific expression, localization, regulation, and function. J Biol Chem 280: 21078-21090, 2005

52. Stone RC, Feng D, Deng J, Singh S, Yang L, Fitzgerald-Bocarsly P, Eloranta ML, Rönnblom L and Barnes BJ: Interferon regulatory factor 5 activation in monocytes of systemic lupus erythematosus patients is triggered by circulating autoantigens independent of type I interferons. Arthritis Rheum 64: 788-798, 2012.

53. Mulens-Arias V, Rojas JM, Pérez-Yagüe S, Morales MP and Barber DF: Polyethylenimine-coated SPIONs trigger macrophage activation through TLR-4 signaling and ROS production and modulate podosome dynamics. Biomaterials 52: 494-506, 2015.

54. Moreno-Fierros L, García-Hernández AL, Ilhuicatzi-Alvarado D, Rivera-Santiago L, Torres-Martínez M, Rubio-Infante N and Legorreta-Herrera M: CrylAc protoxin from Bacillus thuringiensis promotes macrophage activation by upregulating CD80 and CD86 and by inducing IL-6, MCP- 1 and TNF- $\alpha$ cytokines Int Immunopharmacol 17: 1051-1066, 2013.

55. Byun MW: Schizonepeta tenuifolia ethanol extract exerts anti-inflammatory activity through the inhibition of TLR4 signaling in lipopolysaccharide-stimulated macrophage cells. J Med Food 17: 350-356, 2014
56. Chanput W, Mes JJ, Savelkoul HF and Wichers HJ: Characterization of polarized THP-1 macrophages and polarizing ability of LPS and food compounds. Food Funct 4: 266-276, 2013.

57. Jeganathan S, Fiorino C, Naik U, Sun HS and Harrison RE: Modulation of osteoclastogenesis with macrophage M1- and M2-inducing stimuli. PLoS One 9: e104498, 2014.

58. Jarvis JN, Meintjes G, Bicanic T, Buffa V, Hogan L, Mo S, Tomlinson G, Kropf P, Noursadeghi $M$ and Harrison TS: Cerebrospinal fluid cytokine profiles predict risk of early mortality and immune reconstitution inflammatory syndrome in HIV-associated cryptococcal meningitis. PLoS Pathog 11: e1004754, 2015

59. Huang Y, Gao J, Meng XM, Jiang GL, Yang YR, Li H, Liu J and $\mathrm{Li}$ J: Involvement of mitogen-activated protein kinase activation in cyclooxygenase- 2 and transforming growth factor- $\beta$ production in alveolar macrophage from chronic bronchitis rats. Immunopharmacol Immunotoxicol 33: 645-651, 2011

60. Dong L, Wang S, Chen M, Li H and Bi W: The activation of macrophage and upregulation of CD40 costimulatory molecule in lipopolysaccharide-induced acute lung injury. J Biomed Biotechnol 2008: 852571, 2008. 